\title{
Lung Injury in Asphyxiated Newborn Pigs Resuscitated from Cardiac Arrest - The Impact of Supplementary Oxygen, Longer Ventilation Intervals and Chest Compressions at Different Compression-to- Ventilation Ratios
}

\author{
Ingrid Dannevig $^{*}, 1,2,3,4$, Anne L. Solevåg ${ }^{1,2,3,4}$, Ola D. Saugstad ${ }^{3}$ and Britt Nakstad ${ }^{1,2}$ \\ ${ }^{I}$ Dept. of Paediatrics, Akershus University Hospital, N-1478 Lørenskog, Norway \\ ${ }^{2}$ Institute of Clinical Medicine, University of Oslo, N-1478 Lørenskog, Norway \\ ${ }^{3}$ Dept. of Paediatric Research, Oslo University Hospital, Rikshospitalet, P.O Box 4950 Nydalen, N-0424 Oslo, Norway \\ ${ }^{4}$ Institute for Surgical Research, Oslo University Hospital, Rikshospitalet, P.O Box 4950 Nydalen, 0424 Oslo, Norway
}

\begin{abstract}
Introduction: Non-specific lung inflammatory events caused by severe asphyxia may be intensified by the way we resuscitate the newly born. Assessing lung injury is potentially important because if alternative resuscitation approaches induces similar inflammatory responses or less lung injury. then we may choose the resuscitation approach that is most gentle, and easiest to perform and learn. We investigated the levels of lung inflammatory markers by comparing different ventilation, chest compression and inhaled oxygen fraction strategies in resuscitation of newly born pigs at cardiac arrest.
\end{abstract}

Materials and methods: Progressive asphyxia in newborn pigs was induced until asystole occurred. With current resuscitation guidelines as a reference group, pigs were randomized to receive initial ventilation before chest compressions for $30 \mathrm{~s}, 60 \mathrm{~s}$ or $90 \mathrm{~s}$, or to compression-to-ventilation ratios $3: 1$ or 9:3, or to resuscitation using pure oxygen or air. We analysed inflammatory markers in bronchoalveolar lavage fluid (BAL), IL8 and TNF $\alpha$, and lung tissue qPCR for genes matrix metalloproteinases (MMP)2, MMP9, TNF $\alpha$ and ICAM-1.

Results: BAL-levels of TNF $\alpha$ and IL8 tended to be higher in the 30s group compared to 60s group ( $\mathrm{p}=0.028$ and $\mathrm{p}=$ 0.023 , respectively) as was gene expression in lung tissue of ICAM-1 and MMP2 ( $p=0.012$ and $p=0.043$, respectively). MMP2 expression was slightly higher in the 30 s group compared to 90 s group $(p=0.020)$. No differences were found between pigs resuscitated with $\mathrm{C}: \mathrm{V}$ ratio $9: 3$ and $3: 1$ or pure oxygen versus air.

Conclusion: Compared to current guidelines, with respect to lung injury, resuscitation with longer initial ventilation should be considered. Longer series of chest compressions did not change the lung inflammatory response, neither did the use of air instead of pure oxygen in severely asphyxiated pigs resuscitated from asystole.

Keywords: Newborn, asphyxia, lung inflammation, room air, resuscitation, BAL, MMP2, MMP9, TNF $\alpha$, IL8, ICAM-1.

\section{INTRODUCTION}

Little is known about the impact on lung injury resulting from newborn resuscitation itself, but data from clinical studies shows a distinct increase in inflammatory markers in blood early after thoracic trauma, i.e. chest compressions that may cause pulmonary contusion and even rib fractures [1-3]. The resuscitation procedure should address the minimum number of compressions and ventilations delivered and rescuer fatigue. In this study we focus on changes in lung inflammatory markers and if this may be related to the way we resuscitate newly born pigs subjected to hypoxia and reoxygenation. As reperfusion of ischemic myocardium

*Address correspondence to this author at the Department of Paediatrics, Akershus University Hospital, 1478 Lørenskog, Norway; Tel: +47 02900; Fax:+4767961170; E-mail: ingrid.dannevig@medisin.uio.no results in a significant increase of inflammatory markers in plasma, but not in broncholaveolar lavage (BAL), the lungs seem to consume rather than release myocardial derived inflammatory mediators [4]. An increase in lung inflammatory markers could therefore be the result of damaging processes exposed on or within the lung.

The International Liaison Committee on Resuscitation (ILCOR) developed an international consensus on the scientific evidence in the literature relating to newborn resuscitation and, from this, produced today's treatment recommendations. These are pulse oximetry for assessment during newborn resuscitation, to start resuscitation with a $\mathrm{FiO} 2$ of 0.21 and cardiorespiratory resuscitation with a $3: 1$ chest compression/inflation ratio for a heart rate $<60$ beats/min. If persistent asystole or bradycardia, 30s of initial positive pressure ventilation are recommended before start of alternating compressions and ventilations $3: 1$ with $21 \%$ 
oxygen in inspiratory gas, and adrenaline administration if the heart rate remains less than 60 beats per minute [5]. Establishment of effective ventilation is considered to be the primary objective in the management of the apneic or bradycardic newborn infant since need for resuscitation is almost always the result of respiratory problems [6], and the reversal of asphyxia via adequate ventilation is critical in the case of asystole in the newborn. Poorer lung function or acute respiratory insufficiency caused by lung injury may also contribute to the outcome.

Longer duration of time from asystole to return of spontaneous circulation (ROSC) is associated with increased mortality and morbidity with more severe complications such as neurological outcomes [7]. ILCOR recommends stopping resuscitation after $10 \mathrm{~min}$ of adequate resuscitation if there are no signs of life [8]. This is based on observational data on the outcome of infants with an Apgar of 0 at 10 minutes [7] whereas Apgar scores at 5 min [8] as well as at $10 \mathrm{~min}$ provide useful prognostic data before other evaluations of for example hypoxic ischemic encephalopathy [9].

According to Perlman and Risser, chest compressions or adrenaline are administered in $0.12 \%$ of delivery room resuscitations and in approximately two-thirds of these infants improper initial ventilatory support is the presumed mechanism for continued neonatal depression [10]. We have previously reported experimental data on alternative strategies to current recommendations for initial ventilation [11]. Sixty seconds, but not as long as 90s of initial positive pressure ventilation, was as good as 30 s and did not impair the speed or success in achieving ROSC. We have therefore questioned if longer initial ventilation times may reduce lung injury compared to the recommended $30 \mathrm{~s}$ strategies indicating that longer initial ventilation times with shorter periods of chest compressions should be considered.

We further sought to find if alternative compression-toventilation $(\mathrm{C}: \mathrm{V})$ strategies such as $\mathrm{C}: \mathrm{V} 9: 3$, induce less lung injury compared to current $3: 1$ guidelines. We previously showed that these longer series of chest compressions ( 9 or 15 in a row, respectively) produced similar ROSC as the $3: 1$ approach $[12,13]$. Here we aimed to find if the extent of lung injury favors longer series of chest compressions with less frequent ventilations.

Further, we previously reported that air is as effective as pure oxygen in resuscitation of newborn pigs from cardiac arrest, which is an important observation since these pigs were severely asphyxiated with base excess below -30 $\mathrm{mmol} / \mathrm{l}$ and $\mathrm{pH}$ 6.7, and high $\mathrm{PaCO}_{2}$ at asystole [14]. We were interested in finding the impact on lung inflammation when using air versus pure oxygen in this model.

Our group has previously shown that hypoxia followed by reoxygenation with pure oxygen instead of room air, induces increased levels of lung metalloproteinases (MMPs) and IL8 $[15,16]$, however these pigs were not as severely asphyxiated as in this model. This is a study of neonatal resuscitation focusing on changes reflecting lung injury related to hypoxia and reoxygenation following resuscitation from asystole. Here we aimed to find if MMP2 and MMP9, the cell adhesion gene ICAM-1, together with the gene encoding cytokine TNF $\alpha$ are involved in the lung inflammatory response to severe asphyxia followed by alternative ways to resuscitate these pigs. Further, if BAL levels of IL8 and TNF $\alpha$ are modulated by longer initial ventilation times and alternative ratios for $\mathrm{C}: \mathrm{V}$, or if $21 \%$ oxygen versus $100 \%$ oxygen ought to be considered to obtain the optimal strategy for resuscitation of newly born infants.

\section{MATERIALS AND METHODS}

The Norwegian Council for Animal Research approved the experimental protocol. Animals were cared for and handled in accordance with the European Guidelines for Use of Experimental Animals by certified FELASA (Federation of European Laboratory Animals Science Association) researchers.

\section{Surgical Preparation and Anaesthesia}

Seventy-two newborn Noroc pigs (12-36 h of age and $2.0-2.7 \mathrm{~kg}), \mathrm{Hb}>6 \mathrm{~g} / \mathrm{dL}$, and in good general condition were included in the study. The pigs were anaesthetised, tracheotomised, ventilated, surgically prepared and monitored during experiments. The equipment used in these pigs is as previously described for these pigs by Solevåg et al. [12].

\section{Experimental Protocol}

After 60 min of stabilization, the pigs were introduced to progressive asphyxia until asystole by reducing oxygen to $8 \%$, adding $\mathrm{CO}_{2}$ aiming at $\mathrm{PaCO}_{2}$ of $>7 \mathrm{kPa}$, to imitate perinatal asphyxia, and reducing the ventilator rate gradually by 10 breaths per minute every 10 minutes until asystole, which was diagnosed by a mean arterial pressure (MAP) of 0 $\mathrm{mmHg}$, a flat ECG and cardiac auscultation. Pigs were mechanically ventilated (Babylog 8000+, Drägerwerk, Lübeck, Germany) with $21 \%$ oxygen, with an inspiratory time of $0.4 \mathrm{~s}$, peak inspiratory pressure 25 , positive endexpiratory pressure $5 \mathrm{~cm} \mathrm{H}_{2} \mathrm{O}$ and a rate adjusted to achieve a pCO2 between 4.5 and $6 \mathrm{kPa}$. Pigs were randomized (stratified by gender) by drawing folded cards in envelopes (16 pigs in each group). The 90s group included only 8 animals because halfway through the study, times to ROSC in this group was already significantly longer (all pigs) compared to $30 \mathrm{~s}$.

The experimental groups with the current resuscitation guidelines as the reference are presented in Fig. 1. Newborn pigs were resuscitated according to randomization to 1) initial ventilation periods 30s (reference group 1), 60s (group 2) or $90 \mathrm{~s}$ (group 3), all at $\mathrm{C}: \mathrm{V} 3: 1$ and $21 \%$ oxygen 2 ) $\mathrm{C}: \mathrm{V}$ ratio $9: 3$ (group 4 ) after 30 s ventilation in $21 \%$ oxygen 3 ) resuscitation in $100 \%$ oxygen (group 5) at $\mathrm{C}: \mathrm{V} 3: 1$ and $30 \mathrm{~s}$ of initial ventilation. Return of spontaneous circulation (ROSC) was defined as a heart rate of $\geq 100 / \mathrm{min}$. Time to ROSC for all groups are summarized in Table $\mathbf{1}$ and published in previous publications $[11,12,14]$. If there was no ROSC after $15 \mathrm{~min}$ of resuscitation, the efforts were discontinued. If asystole/bradycardia persisted, adrenaline $(0.02 \mathrm{mg} / \mathrm{kg}$ iv) was given after one minute and then every 3 min until a heart rate $\geq 60$ beats per minute were achieved. All pigs required one or more doses adrenaline to obtain ROSC and were observed for 4 hours after resuscitation and maintained in $21 \% \mathrm{O}_{2}$, except for the pigs resuscitated with $100 \%$ O2. These pigs were mechanically ventilated with 


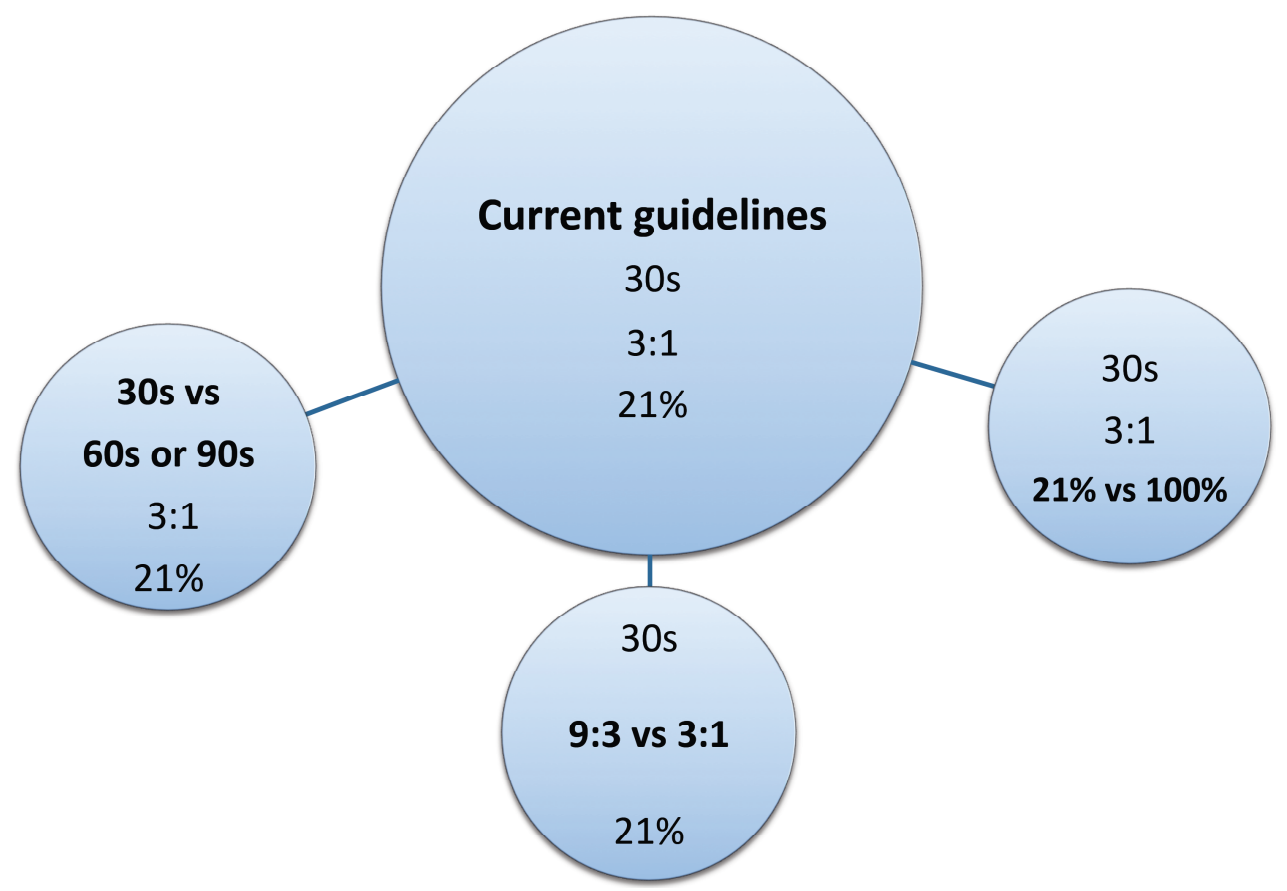

Fig. (1). The newborn resuscitation experimental protocol. Current guidelines as the reference group (central circle). Alternatives to guidelines in bold letters within each circle.

$100 \% \mathrm{O} 2$ for $30 \mathrm{~min}$ after ROSC before switch to $21 \% \mathrm{O} 2$ for the remaining observation. Four animals died, one in the reference group, one in the 90s group did not achieve ROSC and two animals resuscitated with $100 \% \mathrm{O}_{2}$ died during the 4 hour post-resuscitation period. There were no differences in the need for additional midazolam, fentanyl and pentobarbital, these medications only given if there were clinical signs of pain and seizures. For further details see our previous publications $[11,12,14]$.

\section{Sampling}

Post mortem, lung tissue was cut from the caudal part of the left lower lung lobe and immediately frozen in liquid nitrogen and stored at $-80{ }^{\circ} \mathrm{C}$. BAL was then performed using $30 \mathrm{ml} / \mathrm{kg}$ warm saline $\left(38^{\circ} \mathrm{C}\right)$ and aspirated samples were centrifuged at $2000 \mathrm{xg}$ at $4^{\circ} \mathrm{C}$ for $20 \mathrm{~min}$ to pellet cells, the supernatant transferred to polypropylene tubes, immediately frozen in liquid nitrogen and stored at $-80^{\circ} \mathrm{C}$.

\section{Cytokine Analysis of BAL}

Using the Spike and Recovery Immunoassay and Sample Validation Protocol from R\&D systems, Inc (Minneapolis, USA), spike and recovery and linearity experiments were performed on BAL samples. Good values were recorded from the validation experiment. BAL samples were analyzed in singlets with a twofold increase in volume of standard, control and sample added on R\&D systems Quantikine,
Porcine IL8 (P8000) and TNF $\alpha$ (PTA00) Immunoassay following the manufacturer's instructions for cell culture supernatant samples. Samples were measured spectrophotometrically at $450 \mathrm{~nm}$ with wavelength correction set to $540 \mathrm{~nm}$ using Thermo Electron Varioskan reader (Thermo Fisher Scientific Inc, Waltham, MA, USA) and SkanIt Software version 2.2. For automatic calculation of IL8 and TNF $\alpha$ results, the recommended four parameter logistic curve-fit method was used.

\section{Reverse Transcription Quantitative Real-Time PCR (RT-qPCR)}

Homogenization of $30 \mathrm{mg}$ lung tissue samples in $700 \mu \mathrm{l}$ lysis buffer was done using OmniTip (Omni International, USA). Ezna Total RNA purification kit I (Omega Biotek, USA) with DNase (Omega Bio-tek) treatment was used for total RNA isolation. The quantity and quality of total RNA was assessed using the NanoDrop ND-1000 Spectrophotometer (NanoDrop Technologies, USA). The High Capacity cDNA Reverse Transcription Kit (Part Number 4368814, Applied Biosystems, USA) was used for reverse transcription of $2 \mu \mathrm{g}$ of total RNA into complementary DNA (cDNA) using a reaction volume of 40 $\mu 1$. For qPCR, $50 \mathrm{ng}$ cDNA, 400nM of each primer (Table 2) and SYBR Green PCR Master mix were manually pipetted in duplicate on an ABgene 96-well PCR Plate (Thermo Scientific) in a reaction volume of $25 \mu 1$. The plate was run

Table 1. Time to Return of Spontaneous Circulation (ROSC) in Seconds for Randomised Groups 1-5

\begin{tabular}{|c|c|c|c|c|}
\hline ROSC & $\begin{array}{c}\text { Group 1 } \\
\mathbf{3 0 s / 3 : 1 / 2 1 \%}\end{array}$ & $\begin{array}{c}\text { Group 2 } \\
\mathbf{6 0 s / 3 : 1 / 2 1 \%}\end{array}$ & $\begin{array}{c}\text { Group 3 } \\
\mathbf{9 0 s / 3 : 1 / 2 1 \%}\end{array}$ & $\begin{array}{c}\text { Group 4 } \\
\mathbf{3 0 s} / \mathbf{9}: \mathbf{3} / \mathbf{2 1} \%\end{array}$ \\
\hline \hline Median (s) & 150 & $163 \mathbf{3} / \mathbf{3}$ :100\% & 282 & 148 \\
\hline IQR & $115-180$ & $124-177$ & $199-364$ & $116-195$ \\
\hline
\end{tabular}


Table 2. Primers for Quantitative Real-Time PCR (qPCR)

\begin{tabular}{|c|c|c|c|c|c|}
\hline Gene Name & Gene Symbol & & Primer Sequences 5'-3* & Primer Location & $\begin{array}{c}\text { Sequence } \\
\text { Accession Number }\end{array}$ \\
\hline \multirow[t]{2}{*}{$\begin{array}{c}\text { Peptidylprolyl isomerase A } \\
\text { (cyclophilin A) }\end{array}$} & \multirow[t]{2}{*}{ PPIA } & $\mathrm{F}$ & ATA CGG GTC CTG GCA TCT TG & Exon 4 & NM_214353 \\
\hline & & $\mathrm{R}$ & AAC TGG GAA CCG TTT GTG TTG & Exon 4 & \\
\hline $\begin{array}{l}\text { Matrix metallopeptidase } 9 \\
\text { (gelatinase B, }\end{array}$ & \multirow[t]{2}{*}{ MMP9 } & $\mathrm{F}$ & GGC AGC TGG CAG AGG AAT ATC & Intron-exon 1-2 & DQ132879 \\
\hline $\begin{array}{l}\text { 92kDa gelatinase, } 92 \mathrm{kDa} \text { type } \\
\text { IV collagenase) }\end{array}$ & & $\mathrm{R}$ & CTG CTG GAG AAG CTT TAG AGC C & Exon 2 & \\
\hline \multirow[t]{2}{*}{ Gelatinase A } & \multirow[t]{2}{*}{ MMP2 } & $\mathrm{F}$ & CCC GAC GTG GCC AAT TAC & Exon 2 & AF295805 \\
\hline & & $\mathrm{R}$ & ATC CTG TAG GTG ATC TGG GTC TTG & Intron-exon 2-3 & \\
\hline \multirow{2}{*}{$\begin{array}{l}\text { Tumor necrosis factor (TNF } \\
\text { superfamily, } \\
\text { member 2) }\end{array}$} & \multirow[t]{2}{*}{$\mathrm{TNF}$} & $\mathrm{F}$ & TCC ACC AAC GTT TTC CTC ACT & Exon 4 & NM_214022 \\
\hline & & $\mathrm{R}$ & GGA GGT TGA CCT TGG TCT GGT A & Exon 4 & \\
\hline \multirow[t]{2}{*}{$\begin{array}{l}\text { Intercellular adhesion } \\
\text { molecule- } 1\end{array}$} & ICAM-1 & $\mathrm{F}$ & CCT TGA AGC TCC AAA CTT ATG TCC & Intron-exon 3-4 & AF156712 \\
\hline & & $\mathrm{R}$ & GAA ACG GGT GTG CCC ACT T & Exon 4 & \\
\hline
\end{tabular}

on the ABI PRISM 7300 Real-time PCR System (Applied Biosystems) with universal instrument settings. ABI Prism SDS1.3.1 software (Applied Biosystems) was used for initial data analyses. Single peaks, indicating that single amplicons were generated by qPCR were shown by the melting curves. Amplification efficiencies for the different genes were above $90 \%$. Acceptable NTC values were obtained. PPIA (peptidylprolyl isomerise A) was used as a reference gene for normalization. Relative expression was determined by the comparative $\mathrm{C}_{\mathrm{T}}$ method of relative quantification (RQ), calculated with the arithmetic formula $2^{-\Delta \mathrm{Ct}}$, where $\Delta \mathrm{Ct}$ is the normalized signal level in a sample $(\Delta \mathrm{Ct}=\mathrm{Ct}$ of target gene - Ct of reference gene) [17].

\section{Data Analysis}

Power analyses were performed and based on a pilot study to detect a difference of $50 \mathrm{~s}$ (judged as a 'clinically significant' difference) in time to ROSC between treatment arms with a power of $80 \%$ and a type I error rate of $5 \%$ leading to 16 animals in each group. Statistical analysis was performed using SPSS for Windows (SPSS Inc., Chicago, Ill., USA), version 15.0. Two independent samples t-tests were used for symmetrical variables for comparison between groups. Otherwise the Mann-Whitney test was used. Pvalues presented in the text are not Bonferoni-corrected. The GraphPad Prism program (version 5.0c) was used to make graphical presentations.

\section{RESULTS}

\section{Variations in Ventilation Time from Cardiac Arrest to Start of Chest Compressions}

Characteristics of baseline and experimental data during the hypoxia and resuscitation periods are given in our previous paper [11] as well as time to ROSC in Table $\mathbf{1 .}$ Baseline data for group 3 (90s of initial ventilation) differed for heart rate $(180(24) \mathrm{bpm}$, mean $(\mathrm{SD})), \mathrm{pH}(7.31$ (0.03)) and lactate $(1.9(0.2) \mathrm{mmol} / \mathrm{l})$ versus group 1 (151 (21), 7.38 $(0.07)$ and $2.9(0.9)$, respectively, all $p \leq 0.05)$. Immediately after ROSC mean arterial pressure (MAP) was significantly lower and $\mathrm{pCO} 2$ higher (both $\mathrm{p}=0.007)$, in group $3(90 \mathrm{~s})$ versus group $1(30 \mathrm{~s})$ and time to ROSC was significantly longer $(p<0.001)$ [11]. The 90 s group received a higher number of adrenaline doses during resuscitation, since time to ROSC was longer.

\section{Bronchoalveolar Lavage Fluid (BAL)}

Median (IQR) BAL-concentrations of TNF $\alpha$ in pigs resuscitated from asystole were higher in the 30s group (7.9 $\mathrm{pg} / \mathrm{ml}(6.2-17.3)$ ) compared to the $60 \mathrm{~s}$ group $(4.02 \mathrm{pg} / \mathrm{ml}$ (1.7-7.1)) and 90s group (4.15 pg/ml (2.6-6.1)), $\mathrm{p}=0.023$ and $\mathrm{p}=0.015$, respectively (Fig. 2). BAL IL8 was also higher in the $30 \mathrm{~s}$ group $(296.8 \mathrm{pg} / \mathrm{ml}(222.3-527.5))$ compared to $60 \mathrm{~s}$ group $(206.3 \mathrm{pg} / \mathrm{ml}(146-313.8)), \mathrm{p}=0.028$, and no difference was seen between the $30 \mathrm{~s}$ and $90 \mathrm{~s}$ groups $(\mathrm{p}=0.39)$.

\section{Lung Tissue}

Gene expression of genes MMP2, MMP9, ICAM-1 and TNF $\alpha$ are presented in Table $\mathbf{3}$ and Fig. 3. Small differences were found for MMP2 in lung tissue as measured by $2^{\text {-ddCT }}$ which was higher in the group ventilated for 30s (1.1 (0.9$1.4))$ compared to the $60 \mathrm{~s}(0.8(0.6-0.96))$ and 90 s group $(0.6$ $(0.59-0.96)), p=0.043$ and $p=0.02$ respectively, whereas expression of ICAM-1 was higher in the $30 \mathrm{~s}$ group $(1.01$ (0.86-1.09)) compared to $60 \mathrm{~s}(0.82(0.79-0.94)), \mathrm{p}=0.012$.

\section{Variations in Ratios of Chest Compressions-to- Ventilation}

We were unable to discover experimental and hemodynamic differences or differences in time to ROSC between groups (Table 1) [12]. Baseline data were similar in the two groups, except for weight, $\mathrm{HR}$ and $\mathrm{SpO} 2$. In group 4 


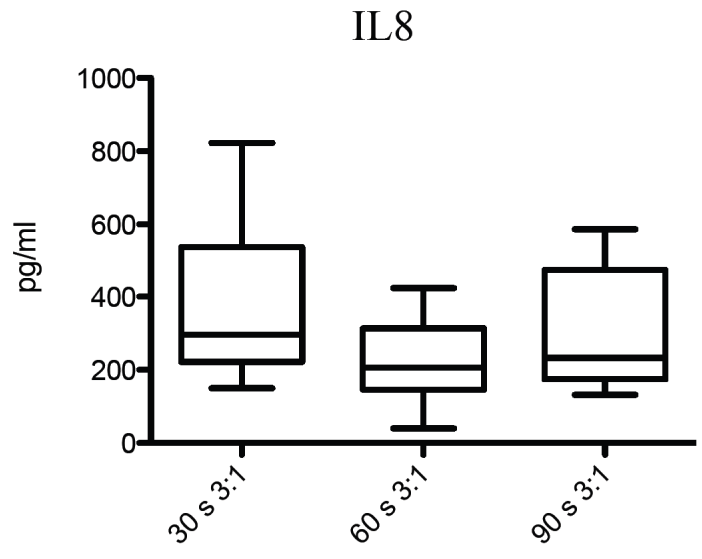

Table 3. Gene Expression RT-PCR in Lung Tissue Expressed as $2^{\text {-ddCt }}$ Median (IQR) for Genes MMP2, MMP9, ICAM-1 and TNF $\alpha$

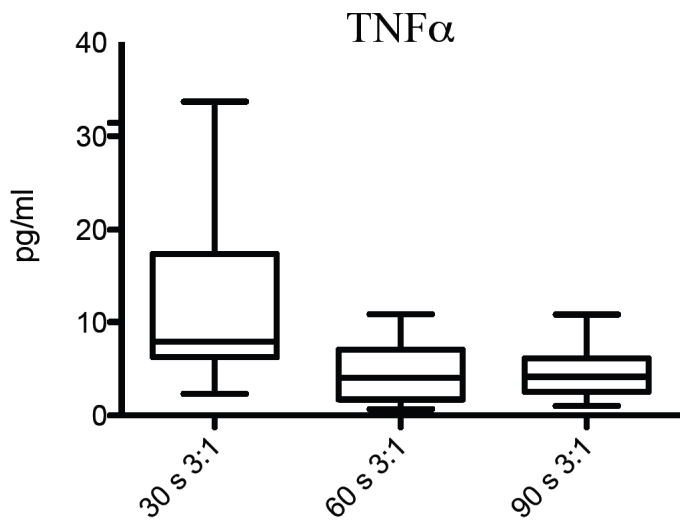

Fig. (2). Boxplots with TNF $\alpha(\mathrm{pg} / \mathrm{ml})$ and IL8 (pg/ml) in BAL comparing the different resuscitation strategies; ventilation for $30 \mathrm{~s}$ (group 1), 60s (group 2) or 90s (group 3) before onset of chest compressions. Results are presented as median (IQR).

(9:3); weight 2402 (119) grams (mean (SD)), HR 230 (18) bpm and SpO2 95 (6)\% versus group 1 (3:1); weight 2270 (152) grams, HR 151 (21) bpm and $\mathrm{SpO} 2$ 90(6)\%, all comparisons $\mathrm{p}<0.05$. No differences in BAL IL8 or TNF $\alpha$ concentrations, or gene expression in lung tissue was seen comparing the two $\mathrm{C}: \mathrm{V}$ ratios 3:1 (group 1) and 9:3 (group 4, Table 3). The ventilation time before start of chest compressions in these groups were $30 \mathrm{~s}$ and they were resuscitated in $21 \%$ oxygen. Baseline and experimental data at asystole and post-resuscitation are given in our previous paper [12] showing no significant experimental or hemodynamic differences. TNF $\alpha$ in BAL in the group 4 resuscitated with a $\mathrm{C}: \mathrm{V}$ ratio of $9: 3$ was $1.26(0.92-1.55)$ and in the $3: 1$ group $1 ; 0.88(0.67-1.28), p=0.047$. IL8 in BAL was $278.2 \mathrm{pg} / \mathrm{ml}(127.3-400.1)$ with a $\mathrm{C}: \mathrm{V}$ ratio of 9:3 (group 4), correspondingly $296.8 \mathrm{pg} / \mathrm{ml}(222.3-537.5)$ with $\mathrm{C}: \mathrm{V}$ ratio $3: 1$ (group 1 ), $\mathrm{p}=0.22$.

\section{Variations in Oxygen Concentration}

We found no clinical or experimental differences between the two groups resuscitated with $21 \% \mathrm{O}_{2}$ (group 1) versus $100 \% \mathrm{O}_{2}$ (group 5), both with initial ventilation time of 30s and $\mathrm{C}: \mathrm{V} 3: 1$. Baseline data differed for age; group 5 (30 (3) h), mean (SD), versus group 1 (26 (6)). Data for gene expressions in lung tissue is given in Table 3 and in BAL $\mathrm{TNF} \alpha$ was $7.93 \mathrm{pg} / \mathrm{ml}(6.24-17.29)$ and $10.57 \mathrm{pg} / \mathrm{ml}$ (3.2917.13 ), respectively for $21 \%$ versus $100 \% \mathrm{O}_{2}, \mathrm{p}=0.85$.

\begin{tabular}{|c|c|c|}
\hline Gene & Vent. Time (s), C:V, oxygen & $2^{-\mathrm{ddCT}}$ Median (IQR) \\
\hline ICAM-1 & $30 \mathrm{~s}, 3: 1,21 \%$ & $1.01(0.87-1.09)$ \\
\hline ICAM-1 & $60 \mathrm{~s}, 3: 1,21 \%$ & $0.82(0.80-0.94) \mathrm{p}=0.01$ \\
\hline ICAM-1 & 90 s, $3: 1,21 \%$ & $0.88(0.84-1.25) \mathrm{p}=0.98$ \\
\hline ICAM-1 & $30 \mathrm{~s}, \mathbf{9 : 3}, 21 \%$ & $1.00(0.85-1.13) \mathrm{p}=0.81$ \\
\hline ICAM-1 & $30 \mathrm{~s}, 3: 1, \mathbf{1 0 0} \%$ & $0.78(0.72-1.08) \mathrm{p}=0.86$ \\
\hline $\mathrm{TNF} \alpha$ & $30 \mathrm{~s}, 3: 1,21 \%$ & $0.88(0.68-1.43)$ \\
\hline $\mathrm{TNF} \alpha$ & $60 \mathrm{~s}, 3: 1,21 \%$ & $0.83(0.62-1.32) \mathrm{p}=0.88$ \\
\hline $\mathrm{TNF} \alpha$ & $90 \mathrm{~s}, 3: 1,21 \%$ & $0.85(0.64-1.96) \mathrm{p}=0.64$ \\
\hline $\mathrm{TNF} \alpha$ & $30 \mathrm{~s}, \mathbf{9 : 3}, 21 \%$ & $1.38(0.86-1.81) \mathrm{p}=0.81$ \\
\hline $\mathrm{TNF} \alpha$ & 30 s, $3: 1, \mathbf{1 0 0} \%$ & $0.98(0.60-1.62) \mathrm{p}=0.79$ \\
\hline MMP2 & $30 \mathrm{~s}, 3: 1,21 \%$ & $1.07(0.85-1.44)$ \\
\hline MMP2 & 60 s, $3: 1,21 \%$ & $0.83(0.63-0.96) \mathrm{p}=0.04$ \\
\hline MMP2 & $90 \mathrm{~s}, 3: 1,21 \%$ & $0.61(0.60-0.96) p=0.02$ \\
\hline MMP2 & $30 \mathrm{~s}, \mathbf{9 : 3}, 21 \%$ & $0.96(0.83-1.15) \mathrm{p}=0.76$ \\
\hline MMP2 & $30 \mathrm{~s}, 3: 1, \mathbf{1 0 0} \%$ & $0.85(0.66-1.02) \mathrm{p}=0.85$ \\
\hline MMP9 & $30 \mathrm{~s}, 3: 1,21 \%$ & $1.32(0.41-1.98)$ \\
\hline MMP9 & 60 s, $3: 1,21 \%$ & $0.98(0.76-1.31) \mathrm{p}=0.75$ \\
\hline MMP9 & 90 s, $3: 1,21 \%$ & $1.82(1.40-2.82) \mathrm{p}=0.18$ \\
\hline MMP9 & $30 \mathrm{~s}, \mathbf{9 : 3}, 21 \%$ & $1.90(1.22-2.85) \mathrm{p}=0.15$ \\
\hline MMP9 & 30 s, $3: 1, \mathbf{1 0 0} \%$ & $1.28(1.04-1.92) \mathrm{p}=0.76$ \\
\hline
\end{tabular}

p-values for comparisons to the control group, i.e. current guidelines, 30 s, $3: 1$ and $21 \%$ oxygen are given. $\mathrm{C}: \mathrm{V}$ chest compressions:ventilations. $30 \mathrm{~s}, 60 \mathrm{~s}, 90 \mathrm{~s}$ refer to time for initial positive pressure ventilation before $\mathrm{C}: \mathrm{V}$ start

Corresponding data for IL8 were $296.8 \mathrm{pg} / \mathrm{ml}(222.3-537.5)$ with $21 \%$ oxygen versus $235.2 \mathrm{pg} / \mathrm{ml}(156.7-412.9)$ with $100 \%$ oxygen $(\mathrm{p}=0.14)$, indicating that the inflammatory response due to oxygen toxicity, at least shortly after asystole and resuscitation trauma, may be exceeded by the injury imposed by cardiac arrest and trauma due to chest compressions. As previously reported [14], ROSC time was independent of the oxygen fraction being 21 or $100 \%$.

\section{DISCUSSION}

Literature and clinical experience support that, when properly performed, positive pressure ventilation alone is effective in the resuscitation of virtually all apnoeic or bradycardic infants [5]. Since ventilation is the most effective action in neonatal resuscitation, the design of these experimental series should ensure that assisted ventilation is being delivered optimally before starting chest compressions. With a focus on lung injury, we aimed to discover if the alternative ventilation and chest compression strategies we present in this model were as good as or better than the present guidelines. In addition, $21 \%$ oxygen versus $100 \%$ oxygen was studied in this model of extreme asphyxia and cardiac arrest in newborn pigs. 
TNF $\alpha$

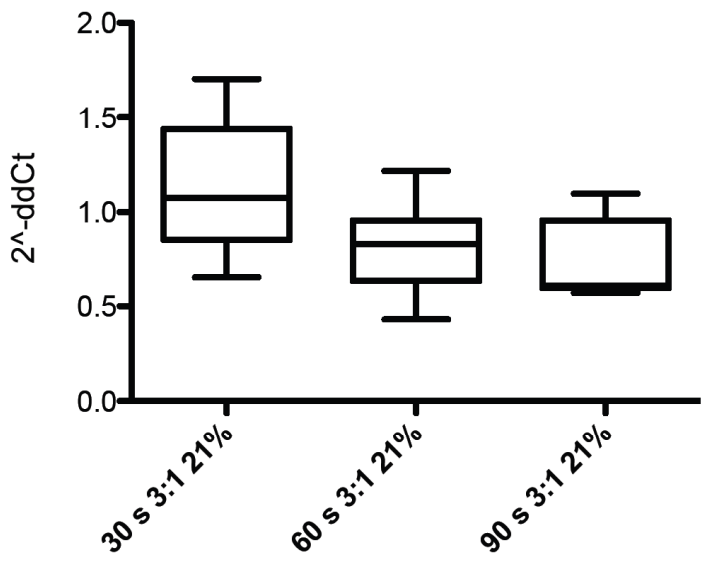

MMP2

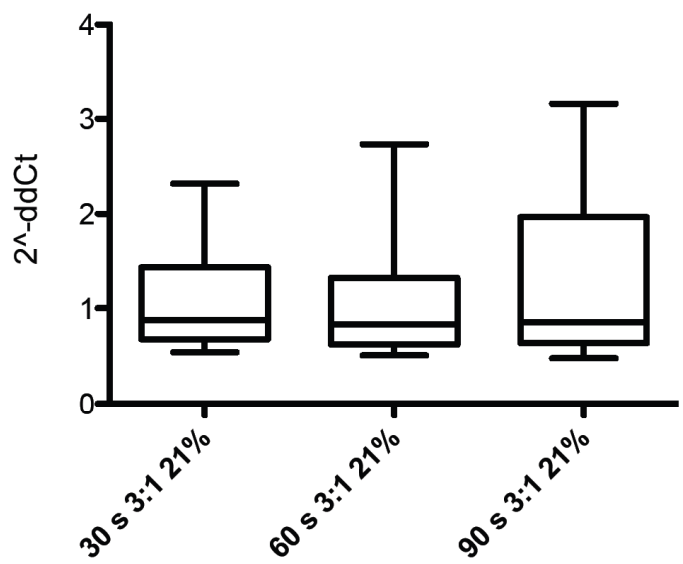

ICAM-1

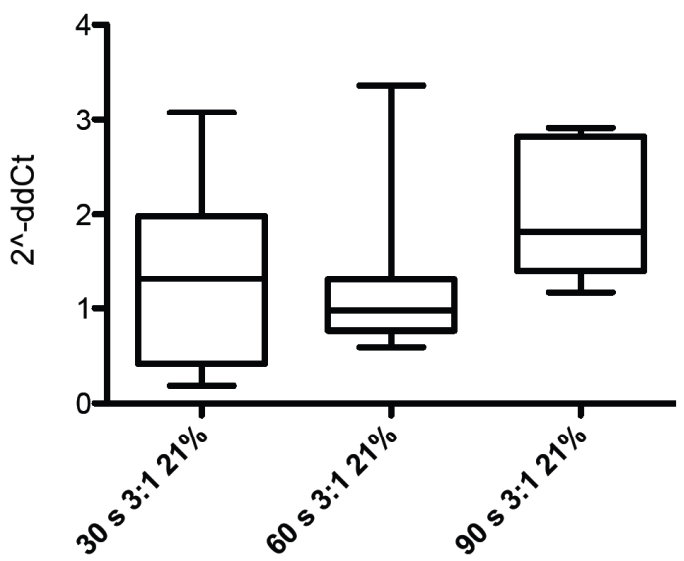

MMP9

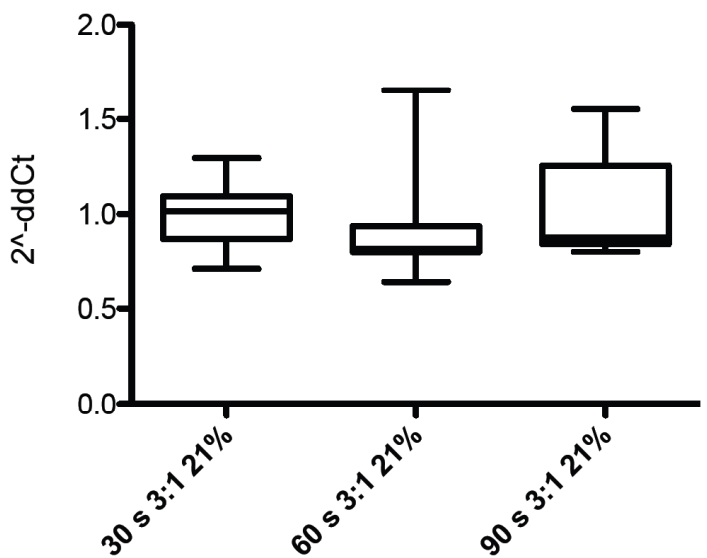

Fig. (3). Boxplots with gene expression expressed as $2^{-\mathrm{ddCT}}$ of MMP2, MMP9, ICAM-1 and TNF $\alpha$ after 60s (group 2) and 90s (group 3) of ventilation prior to chest compressions compared to the present resuscitation guidelines of $30 \mathrm{~s}$ of ventilation and $3: 1$. The results are presented as median (IQR).

In line with clinical experience, compliance with the resuscitation timeline is poor and chest compressions are not applied after $30 \mathrm{~s}$ of initial ventilation, but delayed. Essentially, a prolonged initial ventilation period, between 60 s and 90s, when no cardiac compressions are applied, may be an approach that is worth considering since it tends to less lung injury, at least according to levels of IL8 and TNF $\alpha$ in BAL and inflammatory MMP2 and ICAM-1 gene expressions in lung tissue. According to the literature lower inflammatory responses confer better outcomes, i.e. both the duration of the acute phase of respiratory distress syndrome in the sick newly born and the length of ventilation is associated with better outcome [18]. In clinical newborn sepsis significantly higher levels of inflammatory markers is found in non-survivors compared to survivors [19, 20]. Also, when we ventilate longer before commencing chest compressions, the time to return of spontaneous circulation is as good as current guidelines of 30s [11], and the number of chest compressions needed is lower. It may also be easier to perform, at least in the one-rescuer situation, thereby producing better CPR quality.

According to lung injury markers reported here, initial ventilation for 60 and 90 s produced quite similar, but $30 \mathrm{~s}$ slightly higher lung inflammatory markers, and our previous experimental data on return of spontaneous circulation (ROSC) show that 90s of positive pressure ventilations is too long to wait before we start chest compressions $(p<0.001$ versus 30s) [11]. Time to ROSC was then significantly delayed and hemodynamic outcomes were markedly worsened post-resuscitation.

TNF $\alpha$ and IL8 in BAL and MMP2 and ICAM-1 gene expression in lung tissue were higher with 30 s of initial ventilation compared to 60s, and IL8 in BAL and MMP2 in lung tissue higher with 30 s compared to $90 \mathrm{~s}$, indicating more lung injury when we ventilate for only 30 s before start of chest compressions. However, the inflammatory marker differences are small and possibly of no practical concern so we suggest that the resuscitation strategy that is easiest to perform and teach could be used. These small variations between $30 \mathrm{~s}, 60 \mathrm{~s}$ and 90 s reflect that many factors influence on the intensity of lung injury including the actual number of chest compressions during resuscitation, severity of asphyxia, reoxygenation and the fraction of oxygen used during ventilation, as well as time to return of spontaneous circulation. Based on these results we argue that a longer period between 60 and 90s, with effective, initial ventilation should be considered as an alternative to current guidelines. 
In the special report from the American Academy of Paediatrics describing the 2010 international guidelines for neonatal resuscitation one of the major recommendations is that chest compression-ventilation ratio should remain at 3:1 for neonates unless the arrest is known to be of cardiac etiology, in which a higher ratio should be considered. In two previous papers we reported experimental data on variations in compression-to-ventilation approaches $[12,13]$. No differences between ratios $3: 1$ and $9: 3$ or $3: 1$ versus $15: 2$ could be shown. With a focus on lung tissue and respiratory airways (BAL), we aimed to discover if any of these ratios reduced the inflammatory response. We found no significantly different values for inflammatory gene expressions for MMP2, MMP9, ICAM-1 and TNF $\alpha$ in lung tissue, or TNF $\alpha$ and IL8 levels in BAL and no clinical significance between these resuscitation strategies. In line with this, we suggest that quality of performance, rescuer fatique studies and studies in infants with primary hypoxic, hypercapnic cardiac arrest should be studied to explore and evaluate the issue of best resuscitation strategy.

This pig model mimics the condition of an extremely asphyxiated newborn and it is in these extreme situations that an optimal strategy that minimises injury is of utmost importance. These pigs had a blood $\mathrm{pH}$ of 6.7 and base excess of $-30 \mathrm{mmol} / \mathrm{l}$ and the pigs heart rate and rhythm returned and continued to beat ( $>100$ beats $/ \mathrm{min})$ which persisted until they were euthanized [11, 12, 14]. According to todays guidelines for babies born at term it is best to begin resuscitation with air rather than $100 \%$ oxygen [5]. In line with this it is an important observation that air is as good as pure oxygen to obtain return of spontaneous circulation even in these extremely sick, asystolic pigs. As the strategy should be to find the most gentle and least injuring approach we were interested to find if the air or pure oxygen strategy produced more lung injury. We could not prove any difference between those resuscitated with air versus pure oxygen.

There is now considerable evidence from animal and human studies that hyperoxia itself injures several organs, including the lung. Randomized studies in asphyxiated newborn babies strongly suggest that air is at least as effective as $100 \%$ oxygen $[5,21]$. Our group previously reported that IL8 and MMPs are elevated in asphyxiated newborn pigs using $100 \%$ oxygen instead of $21 \%$ [15, 16], but these pigs were not as sick and resuscitation was begun at a systolic blood pressure below $20 \mathrm{mmHg}$, not at asystole. We did not find differences in inflammatory responses comparing these extremely sick pigs resuscitated with 21 versus $100 \%$ oxygen. This is probably due to several factors leading to injury such as the extreme asphyxia and hypoxia situation, hyperoxia, hypercapnia, possibly volutrauma of the diseased lung, chest, and respiratory organ trauma and the balance between all of these.

Ideally, to explore if there are any differences between the various strategies a time-response experiment should have been performed for every inflammatory marker to define their optimal time point. We did not perform such time-response experiments and we cannot be sure if other time points should have been chosen. This was due to animal ethical considerations, evaluation of cost-benefits and in accordance with Norwegian standards since it would have necessitated an immense number of animals to perform timeresponse experiments for all inflammatory markers and then run a series for everyone. We therefore sought literature and found 4 hours $[2,15,16,22,23]$ post-resuscitation time to be the best general time-point for all parameters. The choice of inflammatory markers to prove lung injury was also based on literature research, i.e. MMPs are important in ischemiareperfusion injury and MMP2 and 9 are increased in multiple pig organs $[15,16]$. Nonspecific inflammatory events following lung injury or severe asphyxia involve IL8 [16, 23], TNF $\alpha$ [22] and ICAM-1 [22, 23]. We may speculate that the longer time from the initial injury until biomarkers are obtained, the more similar they might become and the more difficult it may be to find significant differences since the injury and pathology is severe for all groups in this condition.

A weakness of the study may be that we decided, after careful statistical and ethical considerations and in accordance with Norwegian standards, to stop inclusion in the 90s group at 8 animals as time to ROSC halfway through the study, was already significantly different between 30 s and 90s. Further, time to return of spontaneous circulation [11] and data on all lung inflammatory markers gave identical results whether we did our statistical analyses including all experiments or only the first 8 pigs in each group.

In conclusion, an initial ventilation time between $60 \mathrm{~s}$ and 90 s induces slightly less lung injury than the 30 s guidelines of today. The compression to ventilation ratio of $9: 3$ is as gentle as $3: 1$, according to lung injury markers. This study therefore adds to the literature and is in line with the clinical implications previously published $[7,8,10]$ indicating that as long ventilations and compressions are of good quality we may choose the resuscitation strategy that is easiest to perform and teach. These results show that further discussions and experiments are needed to find the optimal resuscitation strategy in newborns and infants. It is of special interest that $21 \%$ oxygen, with respect to lung inflammatory markers and clinical factors [14], is as good as $100 \%$ in these severely asphyxiated pigs at cardiac arrest.
ABBREVIATIONS
$\mathrm{CPR}=$ Cardiopulmonary resuscitation
ROSC $=$ Return of spontaneous circulation
MAP $=$ Mean arterial blood pressure
$\mathrm{BAL}=$ Bronchoalveolar lavage fluid
HR $=$ Heart rate
$\mathrm{C}: \mathrm{V}=$ Compression-to-ventilation
ILCOR $=$ The International Liaison Committee on Resuscitation
MMP2 = Matrix metalloproteinase 2
MMP9 $=$ Matrix metalloproteinase 9
$\mathrm{TNF} \alpha=$ Tumor necrosis factor alpha
IL8 $=$ Interleukin 8
ICAM-1 = Intracellular adhesion molecule-1
$\mathrm{IQR}=$ Interquartile range
bpm = beats per minute 


\section{CONFLICT OF INTEREST}

The authors confirm that this article content has no conflict of interest.

\section{ACKNOWLEDGEMENTS}

We especially thank Tonje Sonerud for valuable comments and help in optimizing and analysis of cytokinemeasurements. Geir Aamodt and Bettina Kulle Andreassen are specifically thanked for important and valuable statistical help and valuable suggestions. Myra Wyckoff is thanked for discussions and interest in the project protocol and Grete Dyrhaug and Monica Atneosen-Åsegg for optimizing the PCR results. We express gratitude towards the South East Region Health authorities, the Laerdal Foundation of Acute Medicine and the University of Oslo's Foundation at Akershus University Hospital for significant economic contributions to the study.

\section{REFERENCES}

[1] Gebhard F, Pfetsch H, Steinbach G, Strecker W, Kinzl L, Bruckner UB. Is interleukin 6 an early marker of injury severity following major trauma in humans? Arch Surg 2000; 135(3): 291-5.

[2] Strecker W, Gebhard F, Perl M, et al. Biochemical characterization of individual injury pattern and injury severity. Injury 2003; 34(12): 879-87.

[3] Yamada T, Hisanaga M, Nakajima Y, et al. Serum interleukin-6, interleukin-8, hepatocyte growth factor, and nitric oxide changes during thoracic surgery. World J Surg 1998; 22(8): 783-90.

[4] Liebold A, Keyl C, Birnbaum DE. The heart produces but the lungs consume proinflammatory cytokines following cardiopulmonary bypass. Eur J Cardiothorac Surg 1999; 15(3): 340-5.

[5] Perlman JM, Wyllie J, Kattwinkel J, et al. Neonatal resuscitation: 2010 international consensus on cardiopulmonary resuscitation and emergency cardiovascular care science with treatment recommendations. Pediatrics 2010; 126(5): e1319-44.

[6] Wyllie J. Resuscitation of the depressed newborn. Semin Fetal Neonatal Med 2006; 11(3): 158-65.

[7] Harrington DJ, Redman CW, Moulden M, Greenwood CE. The long-term outcome in surviving infants with Apgar zero at 10 minutes: a systematic review of the literature and hospital-based cohort. Am J Obstet Gynecol 2007;196(5):463 e1-5.

[8] Perlman JM, Wyllie J, Kattwinkel J, et al. Part 11: Neonatal resuscitation: 2010 international consensus on cardiopulmonary resuscitation and emergency cardiovascular care science with treatment recommendations. Circulation 2010; 122(16 Suppl 2): S516-38.

[9] Laptook AR, Shankaran S, Ambalavanan N, et al. Outcome of term infants using apgar scores at 10 minutes following hypoxicischemic encephalopathy. Pediatrics 2009; 124(6): 1619-26.

[10] Perlman JM, Risser R. Cardiopulmonary resuscitation in the delivery room. Associated clinical events. Arch Pediatr Adolesc Med 1995; 149(1): 20-5

[11] Dannevig I, Solevag AL, Wyckoff M, Saugstad OD, Nakstad B Delayed onset of cardiac compressions in cardiopulmonary resuscitation of newborn pigs with asphyctic cardiac arrest. Neonatology 2011; 99(2): 153-62.

[12] Solevag AL, Dannevig I, Wyckoff M, Saugstad OD, Nakstad B Extended series of cardiac compressions during CPR in a swine model of perinatal asphyxia. Resuscitation 2010; 81(11): 1571-6.

[13] Solevag AL, Dannevig I, Wyckoff M, Saugstad OD, Nakstad B. Return of spontaneous circulation with a compression:ventilation ratio of 15:2 versus $3: 1$ in newborn pigs with cardiac arrest due to asphyxia. Arch Dis Child Fetal Neonatal Ed 2011; 96(6): F417-21.

[14] Solevag AL, Dannevig I, Nakstad B, Saugstad OD. Resuscitation of severely asphyctic newborn pigs with cardiac arrest by using $21 \%$ or $100 \%$ oxygen. Neonatology 2010 ; $98(1)$ : 64-72.

[15] Solberg R, Andresen JH, Pettersen S, et al. Resuscitation of hypoxic newborn piglets with supplementary oxygen induces dosedependent increase in matrix metalloproteinase-activity and downregulates vital genes. Pediatr Res 2010; 67(3): 250-6.

[16] Munkeby BH, Borke WB, Bjornland $\mathrm{K}$, et al. Resuscitation of hypoxic piglets with $100 \%$ O2 increases pulmonary metalloproteinases and IL-8. Pediatr Res 2005; 58(3): 542-8.

[17] Livak KJ, Schmittgen TD. Analysis of relative gene expression data using real-time quantitative PCR and the 2(-Delta Delta C(T)) Method. Methods 2001; 25(4): 402-8.

[18] Lista G, Castoldi F, Fontana P, et al. Lung inflammation in preterm infants with respiratory distress syndrome: effects of ventilation with different tidal volumes. Pediatr Pulmonol 2006; 41(4): 357-63.

[19] Harris MC, Costarino AT Jr, Sullivan JS, et al. Cytokine elevations in critically ill infants with sepsis and necrotizing enterocolitis. J Pediatr 1994; 124(1): 105-11.

[20] de Bont ES, Martens A, van Raan J, et al. Tumor necrosis factoralpha, interleukin-1 beta, and interleukin-6 plasma levels in neonatal sepsis. Pediatr Res 1993; 33(4 Pt 1): 380-3.

[21] Saugstad OD. Resuscitation of newborn infants: from oxygen to room air. Lancet 2010; 376(9757): 1970-1.

[22] Skrabal CA, Thompson LO, Potapov EV, et al. Organ-specific regulation of pro-inflammatory molecules in heart, lung, and kidney following brain death. J Surg Res 2005; 123(1): 118-25.

[23] von der Hardt K, Kandler MA, Fink L, et al. High frequency oscillatory ventilation suppresses inflammatory response in lung tissue and microdissected alveolar macrophages in surfactant depleted piglets. Pediatr Res 2004; 55(2): 339-46. 